\title{
Análise dos elementos temáticos característicos do gênero literário crônica com vistas a sua hierarquização para fins classificatórios
}

Analysis of characteristic thematic elements from literary gender chronicle aiming its hierarchy for classificatory ends

\section{Maura Duarte Moreira GUARIDO (1) e João Batista Ernesto de MORAES (2)}

(1) Faculdade de Filosofia e Ciências - Unesp, Av. Higyno Muzzi Filho, 737 - Marília - São Paulo - Brasil - CEP: 17525-900, mauraguarido@gmail.com (2) joaoernesto@pq.cnpq.br

\begin{abstract}
Resumen
¿Cómo clasificar exactamente el género crónica? La cuestión surge al constatar que en la Clasificación Decimal de Dewey (CDD) existe sólo una notación para el género crónica (B869.4). A partir de aquí, esta investigación tomó dos caminos: en el primero, se realizó el análisis de los elementos temáticos de lo género literario crónica; en el segundo, el desdoblamiento de la clase B869.4. Como resultado, se obtuvo la siguiente posibilidad de clasificación: Narrativa Personal; Narrativa de Otros; Reflexiones; Poesías; Comportamiento. Se debe resaltar que las categorías arriba descritas representan algunos aspectos que predominan en el texto, sin que se pueda hablar en exclusividad, toda vez que no es raro encontrar más de uno d estos elementos en las crónicas.
\end{abstract}

Palabras clave: Clasificación Decimal de Dewey. Desdoblamiento de números de clasificación. Crónicas. Clasificación.

\section{Introdução}

Uma das feições da crônica contemporânea é a abordagem de temas do cotidiano, sem nenhuma pretensão, na aparência, de tentar um aprofundamento nos temas abordados em seus textos, mantendo sempre um certo tom coloquial, uma aparência de conversa. Porém, este trânsito entre o cotidiano e a literariedade, aqui funcionando como um injetor de perenidade, objetivamente dá à luz a um gênero literário.

Como classificar exatamente este mosaico, esta verdadeira colcha de retalhos de estilos, de motivos e de formas de expressão? A pergunta é feita quando se constata que na Classificação Decimal de Dewey (CDD) há apenas uma notação para o gênero crônica (B869.4), o que causa grandes dificuldades quando um pesquisador

\begin{abstract}
How can we exactly classify the chronicle gender? The question is asked when one verifies that in Dewey's Decimal Classification (DDC) there is only a note to the chronicle gender (B869.4). So, this research has followed in two ways: first, it was made the analysis of characteristic thematic elements from literary gender chronicle; and, second, it was made a development of B869.4. As results, that is, the main themes of chronicles, it was obtained the following possibility of classification: Personal Narrative; Others' Narrative; Reflections; Poetries; Behaviour. It must be emphasized that categories described above represent some predominant aspects inside the text, without exclusiveness, since it is not rare to find more than one element inside chronicles.
\end{abstract}

Keywords: Dewey's Decimal Classification. Classification number decoupling. Chronicles. Classification.

necessita recuperar estas obras a partir dos temas abordados.

A partir de discussões realizadas no grupo de pesquisa Análise Documentária, surgiu a proposta de se oferecer subsídios para o desdobramento da classe B869.4 da Classificação Decimal de Dewey para a crônica.

Desta forma, esta pesquisa caminhou em duas frentes: na primeira, foi feita a análise dos elementos temáticos característicos do gênero literário crônica com vistas a sua hierarquização para fins classificatórios; num segundo momento, foi feito o desdobramento da classe B869.4, objetivando-se inserir na Classificação Decimal de Dewey os resultados da fase anterior. Para fins de análise, foram consideradas as crônicas publicadas no primeiro semestre de 2008, nos 
jornais Folha de São Paulo e O Estado de São Paulo. Considerações sobre a crônica

A origem da palavra crônica está em khronos, que significa tempo em grego. A sua face contemporânea está, porém, ligada a um tempo mínimo, por assim dizer. É o tempo do instante fugaz, de pequenas e grandes alegrias e tragédias do cotidiano, sem a preocupação com a fixação de grandes períodos humanos, como é comum encontrar-se em suas origens (Moraes, 2008, p. 135)

Roncari (1995) define o cronista como o narrador do tempo presente Roncari (1995, p. 15):

O cronista é o sujeito que retrata o tempo, canta a imagem do turbilhão que remexe a ordem do mundo e não deixa nada fixo no lugar. Como o narrador do romance, vê o cotidiano com um olhar estranho, alguém capaz de observar e julgar o movimento, a mudança e alertar para o que tem de extraordinário o que parece corriqueiro, sólido e estabelecido. (...) Sua matéria é o tempo, o movimento e superação, a instabilidade afirmada diariamente pelo órgão ao qual pertence (o jornal), e sua função é lembrar que todos estão no mesmo barco, flutuando nas ondas de um lago que não corre para lugar nenhum.

Por isso é que se pode afirmar que o tempo mínimo parece refletir-se bem no cotidiano das pessoas ditas comuns, do chamado "homem médio". O dia-a-dia destas pessoas está cercado de atos, circunstâncias e acontecimentos tão banais que, justamente devido a essa simplicidade corriqueira, parecem não merecer nenhuma atenção especial nem buscam ser explicadas. Acabam sugerindo a aparência de serem completas em sua existência, não suportando nem merecendo nenhuma análise mais aprofundada. Não merecem manchetes de jornais, nem simpósios, e muito menos estudos científicos para tentar desvendar seus elementos constitutivos, sua organização interna ou seus mecanismos de funcionamento.

Entretanto, estes acontecimentos fazem parte da vida de quase todas as pessoas. Aparentemente sem nenhum encantamento especial, estes pequenos pedaços da vida, bem como seus personagens, parecem sempre estar relegados a um segundo plano, seja por parte da mídia, seja por parte dos registros históricos. A preocupação com o que se passa pelas ruas é o que alimenta a crônica

Porque esta é, ou parece ser, uma das feições da crônica contemporânea: a abordagem de temas do cotidiano, sem nenhuma pretensão, na aparência, de tentar um aprofundamento de temas, mantendo sempre um certo tom coloquial, uma aparência de conversa.
Partindo do lirismo mais exacerbado ao humor mais escrachado, da indignação mais raivosa ao mais puro sentimentalismo, tudo temperado com elementos do cotidiano, ou a partir deles, a crônica é capaz de preservar-se da corrosão temporal, diferentemente do seu principal meio de manifestação, o jornal.

Arrigucci (1987) encontra a mesma afirmação para esta transcendência do efêmero:

Muito próximo do evento miúdo do cotidiano, o cronista deve de algum modo driblá-lo, se não quiser naufragar agarrado ao efêmero. Buscando uma saída literária, as margens de sua terra firme são bastante imprecisas: ele pode estender a ambigüidade à linguagem e às fronteiras do gênero, sem perder o nível de estilo adequado às pequenas causas de que trata.

Com isso, às vezes a prosa da crônica se torna lírica, como se estivesse tomada pela subjetividade de um poeta de instantâneo, que, mesmo sem abandonar o tom de conversa fiada, fosse capaz de tirar o difícil do simples, fazendo palavras banais alçarem vôo. Outras vezes a tendência é para a prosa de ficção, pela ênfase na objetivação de um mundo recriado imaginariamente: ela pode se confundir com o conto, a narrativa satírica, a confissão. Outras ainda, como em tantos casos conhecidos, constituem um caso difícil de classificar: é a crônica.

Como classificar exatamente este mosaico, esta verdadeira colcha de retalhos de estilos, de motivos e de formas de expressão?

Pode ser encontrada em Coutinho (1976) uma tentativa de classificação baseada na natureza dos assuntos ou pelo movimento interno Coutinho (1976, p. 80).

Assim temos: a) a crônica narrativa, cujo eixo é uma história, o que a aproxima do conto (...); b) a crônica metafísica, constituída de reflexões mais ou menos filosóficas sobre os acontecimentos ou os homens, como é o caso de Machado de Assis e Carlos Drummond de Andrade, que encontram sempre ocasião e pretexto nos fatos para dissertar ou discretear filosoficamente; c) a crônica-poema em prosa, de conteúdo lírico, mero extravasamento da alma do artista ante o espetáculo da vida, das paisagens ou episódios para ele significativos, como é o caso de Manuel Bandeira, Ledo Ivo; a crônica-comentário dos acontecimentos que tem, no dizer de Eugênio Gomes, o aspecto de um "bazar asiático", acumulando muita coisa diferente o díspar, como são muitas coisas de Alencar, Machado e outros.

Moraes (2008, p. 141) faz alguns reparos a respeito da classificação proposta por Coutinho. Segundo o autor, a última categoria (crônicacomentário) pode também englobar as duas 
categorias iniciais: em menor grau a primeira (crônica narrativa) e quase totalmente a segunda (crônica metafísica).

A crônica narrativa parece não se distanciar muito da crônica-comentário uma vez que, na maioria dos casos há naquela uma intenção, ela apresenta sempre um comentário implícito por trás da narrativa.

Um dos exemplos é a crônica Notícia de Jornal1, de Fernando Sabino. Num belíssimo efeito estilístico, a repetição da expressão "morreu de fome" serve como uma marcação da indignação do cronista diante do fato de um homem ficar estendido na calçada por três dias para, sem que ninguém fizesse nada, acabar morrendo de fome. A preocupação do autor é clara, apesar de, aparentemente, dizer ironicamente o contrário no texto: Que é que eu tenho com isso? Deixa o homem morrer de fome.

Quando Coutinho se refere a crônicas com reflexões "mais ou menos filosóficas", ao definir a categoria crônica metafísica, acaba por oferecer uma "não-definição", uma vez que a falta de precisão na expressão "mais ou menos" deixa em aberto uma grande possibilidade de inclusão desta categoria em uma mais ampla, a crônicacomentário, que por ser abrangente, pode perfeitamente incluir a primeira definição.

A crônica de Fernando Sabino pode servir também para ilustrar que a crônica-comentário, a crônica narrativa e a crônica-poema em prosa não andam muito distantes uma da outra. Não há como negar que são extremamente poéticos os jogos de palavras que o autor faz, como em:

O comissário de plantão (um homem) afirmou que o caso (morrer de fome) era da alçada da Delegacia de Mendicância, especialista em homens que morrem de fome. E o homem morreu de fome.

Neste segmento, pode-se observar que o autor mantém o mote de sua crônica, e o estilo repetitivo, com efeitos retóricos. Ao identificar o comissário de plantão como um homem, o autor busca aproximar o mendigo que está morrendo de fome na calçada de uma autoridade. Como efeito, há uma ampliação dos efeitos do ato desumano de se abandonar alguém agonizando de inanição no meio fio (Moraes, 2008, p. 145).

Deve-se notar ainda que Coutinho não faz nenhuma menção às crônicas que possuem como característica o humor, seja ele descompromissado ou com objetivo de sátira política, como uma das possibilidades do gênero. Pode-se até tentar encaixá-las dentro das categorias de crônica narrativa ou crônica-comentário. Porém, a sátira política vai um pouco além de um simples comentário. Seu objetivo é antes uma tentativa de moralização dos costumes, uma de suas características. Em todo caso, Coutinho não explica o humor presente nas crônicas e do qual ele não faz menção de registrar nem mesmo a existência.

\section{A classificação}

Classificar é dividir em grupos ou classes, segundo as diferenças e semelhanças. É dispor os conceitos, segundo suas semelhanças e diferenças em certo número de grupos metodicamente distribuídos.

É um processo mental habitual ao homem, pois vivemos automaticamente classificando coisas e idéias, a fim de as compreender e conhecer.

A palavra classificar vem do latim classis, que designava os grupos em que se dividia o povo romano. Foi cunhada por Zedler, em 1733, no Universal Lexicon, combinando as palavras latinas classis e facere, para apresentar uma divisão de apelações de Direito Civil e, só no fim do século XVIII, passou a ser empregada para a ordenação das ciências.

Classificar visa a identificar o conteúdo dos documentos conhecidos, com duas características próprias: determinar um lugar para o conteúdo numa coleção organizada por assunto; utilizar um sistema de classificação bibliográfico para representar os assuntos.

Segundo Ranganathan classificar consiste em traduzir o nome dos assuntos dos documentos da linguagem natural para a linguagem artificial utilizada por um sistema de classificação.

A técnica da classificação pressupõe duas etapas: a análise conceitual e a tradução. Intelectualmente, são etapas totalmente distintas, embora nem sempre sejam diferenciadas com clareza e possam, de fato, ocorrer de modo simultâneo.

A análise conceitual implica decidir do que trata um documento, isto é, qual o seu assunto, a partir da formulação de perguntas que supram os propósitos de geração ou recuperação de informações.

A tradução envolve a conversão da análise conceitual de um documento num determinado conjunto de termos de indexação, ou seja, é o esforço de representar a substância da análise conceitual pelo emprego de termos extraídos de alguma forma de vocabulário controlado.

\subsection{Vocabulário controlado}

É uma lista de termos autorizados. Em geral, o classificador somente pode atribuir a um docu- 
mento termos que constem da lista adotada pela instituição para a qual trabalha.

Comumente, no entanto, o vocabulário controlado é mais do que uma mera lista. Inclui, em geral, uma forma de estrutura semântica, destinada a:

- controlar sinônimos, optando por uma única forma padronizada, com remissivas de todas as outras

- diferenciar homógrafos

- reunir ou ligar termos cujos significados apresentem uma relação mais estreita entre si.

Dois tipos de relações são identificadas: as hierárquicas e as não-hierárquicas ou associativas.

\subsection{Sistemas de classificação}

Sistema de Classificação ou Tabela de Classificação é um conjunto de classes apresentado em ordem sistemática. É uma distribuição de um conjunto de idéias por um certo número de conjuntos parciais, coordenados e subordinados.

Um sistema de classificação inclui disciplinas e fenômenos. As disciplinas são ramos do conhecimento, ou formas de conhecimento, que estudam um conjunto de fenômenos relacionados ou correlatos.

Os sistemas são estruturados hierarquicamente e podem ser de dois tipos: sistemas précoordenados e sistemas pós-coordenados. Os primeiros combinam ou coordenam os termos no momento da classificação. É o que acontece com a Tabela Única de Assuntos. Os segundos, no momento da busca e, em regra, são utilizados nas grandes bases de dados de recuperação de assuntos.

\subsection{Modulação}

$\mathrm{Na}$ divisão de uma classe em subdivisões menores e sucessivas, nenhum nível deve ser omitido, nenhuma característica importante deve ser esquecida de ser tomada para base de subdivisão. Entende-se por modulação a apresentação gradativa dos vários níveis de subdivisão.

\subsection{Termo}

A palavra ou as palavras que expressam as idéias num sistema de classificação denominam-se termos ou descritores.

\subsection{Remissivas e decisórias}

A utilização de vocabulários controlados ou tabelas de classificação pressupõe optar por uma forma de representação do assunto em detrimento de outra. Já que a classificação traduz expressões da linguagem natural do dia a dia para os sistemas classificatórios que são linguagens artificiais, é recomendável a confecção de índices de remissão que vão apontar o termo a ser usado para as diversas possibilidades de expressão de um assunto.

Sempre que for escolhido um padrão, deve-se registrar em decisórias a orientação adotada. Um manual de procedimentos, por exemplo, pode comportar essas decisórias.

Nas decisórias devem ficar registradas, para auxílio do classificador, todas as variações afetas às escolhas. Como classificar é uma atividade intelectual, tem alto grau de subjetividade.

Assim, o emprego do singular, ao invés do plural, o controle de sinonímia, dos homônimos, dos regionalismos, o grau de especificidade (em que nível da tabela classificar), podem estar documentados em manual de procedimentos.

\subsection{Categorias e classes}

Categorias são as maiores classes de fenômenos, as classes mais gerais que podem ser formadas. As categorias são, portanto, as grandes classes, os grandes tipos de fenômenos presentes no conhecimento em geral ou numa de suas partes. Classe é um conjunto de coisas ou idéias que possuem um ou vários atributos, predicados ou qualidades em comum.

\subsection{Ordem das tabelas}

A ordem de apresentação dos conceitos nas tabelas de um sistema de classificação deve seguir, primordialmente, a ordem de dependência e a ordem do geral ao específico.

Ranganathan estabeleceu a ordem das categorias, o PMEST, e nove princípios para determinar a ordem de facetas (gêneros) e focos (espécies), que reduziremos as sete seguintes:

1. Extensão decrescente (o mais geral precedendo o mais concreto);

2. Concreção crescente (o mais abstrato precedendo o mais concreto);

3. Complexidade crescente (o mais simples precedendo o mais complexo);

4. Ordem cronológica, incluindo a ordem evolutiva;

5. Ordem de proximidade;

6. Ordem tradicional; 
7. Ordem alfabética (quando nenhuma das outras se impõe).

\subsection{Notação ou Símbolos de classificação}

Símbolo de classificação é o conjunto de caracteres que representam um determinado assunto em um sistema de classificação.

A principal finalidade da notação é localizar os assuntos dentro do sistema, oferecendo um meio para remeter do índice às tabelas do sistema de classificação aos documentos, além de possibilitar a ordenação dos próprios documentos pelos assuntos de que tratam.

A notação oferece, ainda, símbolos que podem ser combinados com outros para indicar os assuntos complexos e compostos.

A notação deve possuir as seguintes qualidades:

1. Indicar a ordem dos assuntos de modo claro e automático, a fim de permitir a localização da informação procurada;

2. Permitir revelar integralmente $o$ assunto do documento (especificidade);

3. Ser hospitaleira, isto é, permitir o número de subdivisões necessárias a cada assunto;

4. Ser flexível ou expansiva, isto é, permitir a inclusão de novos assuntos nas posições mais convenientes;

5. Ser fácil de lembrar, falar e escrever;

6. Ser breve e simples;

7. Revelar a estrutura da classificação, a sua hierarquia, isto é, mostrar as classes relacionadas $\mathrm{e}$ as classes subordinadas (expressividade);

8. Ser mnemônica.

Estas qualidades são ideais, mas dificilmente uma notação reúne todas elas. Porém, símbolos de classificação curtos e simples são mais fáceis de lembrar, falar e escrever.

\section{9. Índice}

O índice de um sistema de classificação é uma lista alfabética dos seus termos e respectivos sinônimos, indicando os símbolos de classificação que representam. As funções do índice alfabético são:

1. Traduzir a linguagem natural em símbolos de classificação;

2. Reunir os assuntos relacionados dispersos, oferecendo como que uma outra classificação, sob bases diferentes.
O índice ainda auxilia a manutenção da uniformidade e da consistência no classificar, evitando classificações diferentes para um mesmo assunto.

O propósito principal da elaboração de índices é construir representações de documentos numa forma que se preste à sua inclusão em algum tipo de base de dados.

\section{Corpus analisado}

Para fins de análise, foram consideradas as crônicas publicadas no primeiro semestre de 2008, nos jornais Folha de São Paulo e O Estado de São Paulo, dos autores Luis Fernando Verissimo, João Ubaldo Ribeiro, Carlos Heytor Cony.

\section{Resultados}

Quanto aos temas, obteve-se a seguinte possibilidade de classificação.

- Narrativa Pessoal - apresenta historietas do cotidiano, geralmente tendo como personagem o próprio cronista.

- Narrativa dos Outros - apresenta historietas do cotidiano, geralmente tendo como personagem outros personagens que não o cronista. Geralmente, apresentam tipos do cotidiano, que se destacam na multidão, ou tipos que ficaram marcados na memória.

- Reflexões - são considerações sobre alguns aspectos do cotidiano, eventualmente sobre as instituições governamentais.

- Poesias - colocou-se esta categoria principalmente em função do cronista Luis Fernando Verissimo e sua série Poesia numa hora dessas?

- Comportamento - análises sobre comportamentos humanos, refletidos no cotidiano, sobre alteração ou manutenção de hábitos.

Deve-se ressaltar que as categorias acima descritas representam alguns aspectos que predominam no texto, nunca podendo falar-se em exclusividade, uma vez que não é raro encontrar-se mais de um elemento nas crônicas.

Quanto ao desdobramento, a partir da análise obteve-se o seguinte resultado:

B 869.4 Crônicas, ensaios, outros tópicos especiais

\section{B 869.41 Poesia}

Classificar aqui poesias publicadas em sessões de crônicas 


\section{B 869.421 Narrativa pessoal}

Classificar aqui historietas do cotidiano, geralmente tendo como personagem o próprio cronista

B 869.422 Narrativa dos outros

Classificar aqui historietas do cotidiano, geralmente tendo como personagens outros que não os cronistas

\section{B 869.43 Reflexões}

$\begin{array}{llcr}\text { Classificar aqui } & \text { considerações } & \text { sobre } \\ \text { alguns aspectos } & \text { do cotidiano } & \begin{array}{r}\text { even- } \\ \text { instituições }\end{array} & \text { sociais } \\ \text { tualmente sobre } & \text { instín } & \end{array}$

\section{B 869.44 Comportamento}

Classificar aqui análises sobre comportamentos humanos, refletidos no cotidiano, sobre alteração ou manutenção de hábitos.

\section{Considerações finais}

A CDD (Classificação Decimal de Dewey) apresenta em seus esquemas facilidades de uso e aplicabilidade de suas classes. Entretanto, algumas classes não são muito expandidas o que dificulta a classificação de alguns assuntos mais específicos.

Por ser um sistema decimal, e em função de sua notação pura (só números), é permitido ao classificador desdobramentos e/ou expansões de algumas classes, como é o caso da classe 869 - Literatura Portuguesa.

O português é uma língua tanto em Portugal como no Brasil, além de uma série de países. Por este motivo, a literatura brasileira muitas vezes é confundida com a literatura portuguesa. Assim, o próprio Comitê editorial da CDD recomenda em nota explicativa que é opcional distinguir as literaturas utilizando-se a letra inicial de cada país antes da notação de classificação, como por exemplo: B 869 - Literatura Brasileira.

A expansão da classe B 869.4 não se limitou apenas à proposta de expansão em si das crônicas brasileiras, mas este estudo visou a oferecer mais uma colaboração para o estudo da tematização da narrativa.

\section{Notas}

(1) Sabino, F. - A mulher do vizinho. Rio: Editora Sabiá, $4^{a}$ ed., pág. 40-42

\section{Referências}

Arrigucci Jr., D. (1987). Enigma e comentário: ensaios sobre literatura e experiência. São Paulo: Companhia das Letras, 1987.

Coutinho, A. (1976). Notas de teoria literária. Rio de Janeiro: Civilização Brasileira, 1976.

Dewey, M. (2003). Dewey decimal classification and relative index. Dublin, Oh: OCLC, 2003.

Moraes, J. B. E. (2008). Análise documental de crônicas: reflexões sobre uma trajetória de interlocução entre literatura, lingüística e ciência da informação. // Guimarães, J. A. C.; Fujita, M. S. L. (Orgs.). Ensino e pesquisa em Biblioteconomia no Brasil: a emergência de um novo olhar. São Paulo: Editora Cultura Acadêmica, 2008. 134145.

Roncari, L. (1985). A estampa da rotativa na crônica literária. // Boletim Bibliográfico da Biblioteca Mário de Andrade. São Paulo. 46:4 (jan. a dez 1985) 17-42. 